\section{Preserve and protect your treatment centre}

The cleaning and disinfection of your treatment centre will preserve its life as well as protecting both patients and staff against infection. That is why Belmont has developed a range of care products to ensure their new equipment retains its aesthetics.

The products can be divided into two categories: chair maintenance (B100 \& B300) and dental unit waterline protection (B700 \& B900).

Chairs need to be wiped down between patients and for such regular use you need a fast-acting upholstery cleaner that will not damage artificial leather; B300 does just that. It has reduced levels of alcohol so that over time it will prevent brittle, cracked surfaces. However, it is bactericidal (even killing TB), yeasticidal and has limited virucidal impact, being effective against non-enveloped viruses, including norovirus.

The perfect adjunct to this is B100, an intensive cleaner designed for occasional use, to remove stains of all kinds as well as discolouration. Despite its rigorous cleaning action, it will not damage your upholstery.

The daily care of your waterlines is another routine hygiene task that must be carried out. B700 is a tried and tested maintenance solution for waterlines. It maintains the water flowing through your unit and will minimise the potential for biofilm formation. B700 is supplied in a single-dose sachet. B700 is also non-effervescent, which means it can be used instantly.

\section{Training provider will support new ortho diploma}

IAS Academy has been named preferred training provider for the launch of an orthodontics qualification.

The College of General Dentistry (CGDent) - the first independent college for primary care dentistry and authoritative body for standards in practice - this week announced IAS Academy is to provide training for its Diploma in Primary Care Orthodontics (DipPCOrth) launching on 20 February 2020.

The academy will offer delegates a combination of hands-on and theoretical study delivered on-campus and online over 14 months in preparation for the diploma examination.

The advanced training syllabus covers assessment, diagnosis, treatment planning and provision using the complete range of orthodontic appliances.

Students will also gain an understanding of the science of orthodontics, as well as the evidence and research underpinning care.

The advanced course that IAS has designed has been developed and refined with great care. It gives delegates a comprehensive understanding of orthodontic principles, allowing them to provide the full range of treatments to an extremely high standard.

The IAS Academy's Advanced Training programme is now open for admissions. The course covers five modules over 14 months lasting 3-4 days each. Training takes place every 2-3 months, and the course also includes one-to-one mentoring of 20 cases for each student.

For more information, visit www.cgdent.uk.

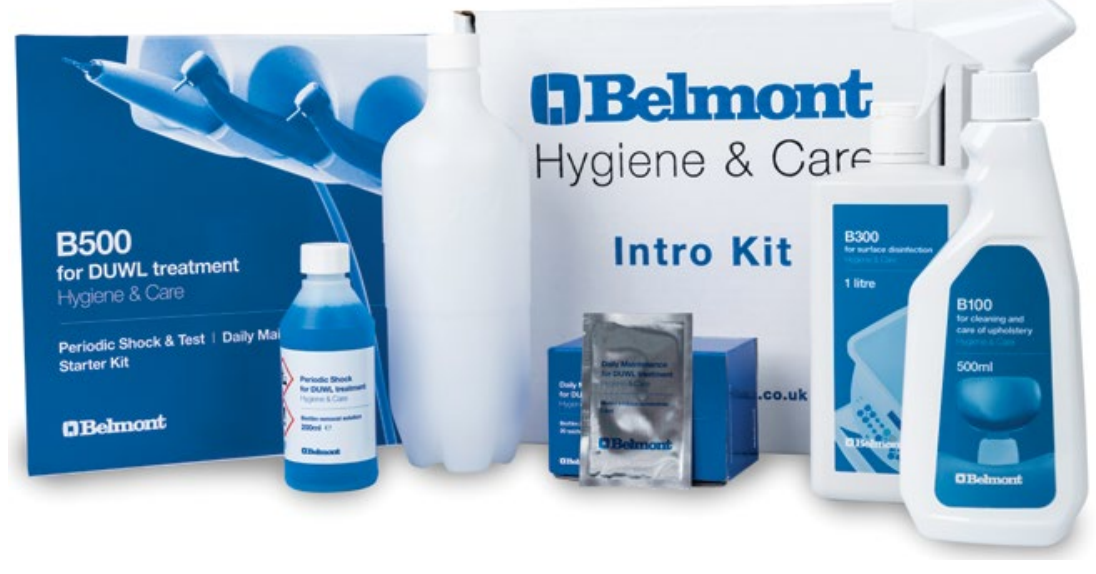

Before you start using B700 it is essential that you test and 'shock' your system using the B900 kit. This will remove any existing biofilm. Thereafter, you're advised to perform this quarterly to prevent the build-up of future biofilm. The B900 kit contains a box of five shock bottles, tester strips and ten dipstick slides for 'before' and 'after' evaluation.

For your convenience Belmont have also put together a starter kit, called B500, so that you can test and treat your water lines with minimal investment.

Whether you have a new or older Belmont unit, you can contact your dealer to order products from the range and ensure your unit remains looking and functioning optimally.

\section{Save time without a compromise}

Finding ways to provide efficient and predictable clinical procedures is important for dental professionals to make the most of the time they have with patients. Streamlining workflows and utilising easy-to-use solutions facilitate this without compromising the quality of treatment.

RelyX Unicem 2 self-adhesive resin cement from $3 \mathrm{M}$ is one such product that simplifies workflows whilst maintaining high standards. It's no wonder RelyX Unicem 2 self-adhesive resin cement has received numerous awards for its clinical performance.

RelyX Unicem 2 self-adhesive resin cement requires no priming, bonding or etching, and is the right consistency for a wide range of applications. Further still, excess cement can be removed easily resulting in next to no post-operative sensitivity and delivers stable aesthetics.

For more information, call 01509380090 or visit www.3M. co.uk/Dental.

$3 \mathrm{M}$ and RelyX are trademarks of the $3 \mathrm{M}$ Company.

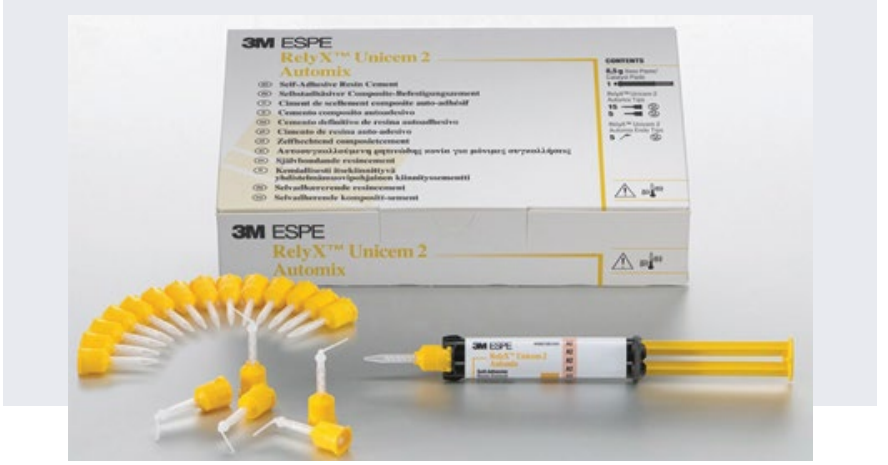

